\title{
Highly Ordered Sub-10 nm Patterns Based on Multi-Chain Columns of Side-Chain Liquid Crystalline Polymers
}

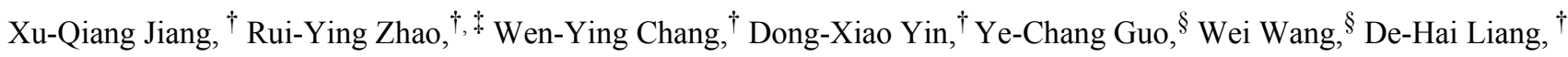
Shuang Yang, ${ }^{*}{ }^{\dagger}$ An-Chang Shi, ${ }^{,}{ }^{\perp}$ Er-Qiang Chen*, ${ }^{\dagger}$

${ }^{\dagger}$ Beijing National Laboratory for Molecular Sciences, Key Laboratory of Polymer Chemistry and Physics of Ministry of Education, Center for Soft Mater Science and Engineering, College of Chemistry and Molecular Engineering, Peking University, Beijing 100871, China

*Academy for Advanced Interdisciplinary Studies, Peking University, Beijing 100871, China

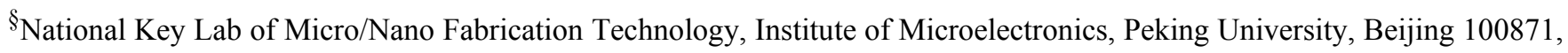
China

${ }^{\perp}$ Department of Physics and Astronomy, McMaster University, Hamilton, Ontario L8S 4M1, Canada 


\section{Contents}

1. Synthesis and Molecular Characterization

2. Instruments and Measurements

3. Solution Light Scattering

4. Molecular Mechanics Simulation on P1

5. Reconstruction of Relative Electron Density Map (EDM) of M1 and P1

6. Figures and Tables

7. References 


\section{Synthesis and Molecular Characterization}

\section{Materials}

Tetrahydrofuran (THF) and dichloromethane (DCM) were dried over calcium hydride and then distilled. Other solvents were purchased in HPLC quality. Grubbs catalyst (third generation) and exo-5-norbornenecarboxylic acid (97\%) were purchased from Sigma-Aldrich and used as received. All the other chemicals were obtained from J\&K Chemicals (Beijing, China) and used without further purification. Thin layer chromatography (TLC) was used to monitor the process of reaction. Flash column chromatography was performed with silica gel (230-400 mesh).

\section{Synthesis Procedures.}

The chemical structures and synthesis routes of monomer M1 and polymer P1 are illustrated in Scheme S1. The experimental details are described as follows ${ }^{[1]}$ :

Scheme S1. Synthesis routes of M1 and P1

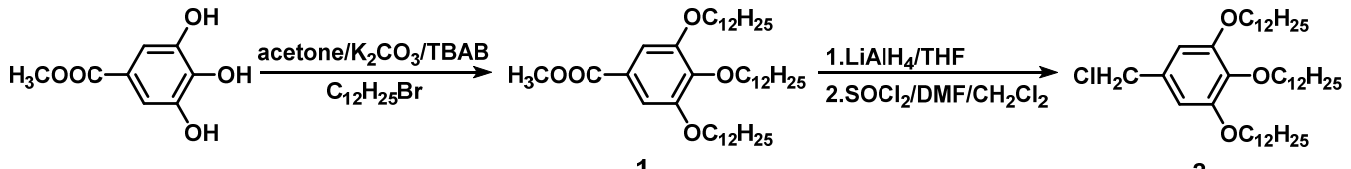

1

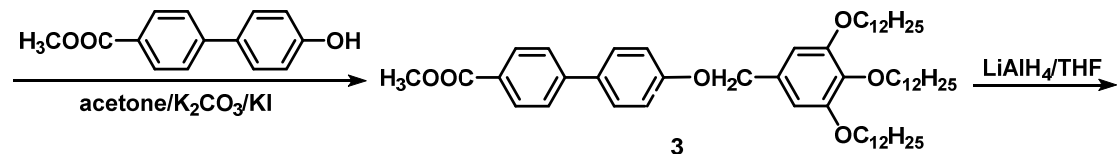<smiles>CCOc1cc(COc2ccc(-c3ccc(CO)cc3)cc2)cc(OCC)c1OCC</smiles><smiles>CCCCOc1cc(COc2ccc(-c3ccc(COc4ccc(-c5ccc(C(=O)OCC)cc5)cc4)cc3)cc2)cc(OCC)c1OCC</smiles><smiles>CCCCCCCCCCCCO</smiles><smiles>CCCOc1cc(COc2ccc(-c3ccc(COc4ccc(-c5ccc(COC(=O)[C@@H]6C[C@H]7C=C[C@H](C7)C6C(=O)O)cc5)cc4)cc3)cc2)cc(OCC)c1OCC</smiles>

M1

Grubbs 3rd $\mathrm{CH}_{2} \mathrm{Cl}_{2}, \mathrm{rt}, 2 \mathrm{~h}$ 


\section{Methyl 3,4,5-tris(dodecyloxy)benzoate (1)}

Methyl 3,4,5-trihydroxybenzoate (10.00 g, 54 mmol), 1-bromododecane (48.59 g, $195 \mathrm{mmol}), \mathrm{K}_{2} \mathrm{CO}_{3}$ (44.91 g, 325 mmol), catalytic amounts of tetrabutylammonium bromide (TBAB), and $300 \mathrm{~mL}$ acetone were added to a $500 \mathrm{~mL}$ round-bottom flask. The mixture was refluxed overnight under stirring. Then the mixture was filtered to remove the insoluble salt. The crude product was purified by column chromatography using petroleum ether as the eluent. Methyl 3,4,5-tris(dodecyloxy)benzoate was obtained as white solid in yield of $80.0 \% .{ }^{1} \mathbf{H}$ NMR $\left(400 \mathrm{MHz}, \mathrm{CDCl}_{3}, \delta, \mathrm{ppm}\right)$ : $7.25(\mathrm{~s}, 2 \mathrm{H}), 4.03-3.99(\mathrm{~m}, 6 \mathrm{H}), 3.89(\mathrm{~s}, 3 \mathrm{H}), 1.84-1.70(\mathrm{~m}, 6 \mathrm{H}), 1.51-1.44(\mathrm{~m}, 6 \mathrm{H}), 1.39-1.20(\mathrm{~m}, 48 \mathrm{H}), 0.88(\mathrm{t}, J=$ $6.8 \mathrm{~Hz}, 9 \mathrm{H}) .{ }^{13} \mathrm{C}$ NMR $(100 \mathrm{MHz}, \mathrm{CDCl} 3, \delta, \mathrm{ppm}): 166.93,152.79,142.30,124.62,107.90,73.46,69.12,52.09$, 31.91, 30.92, 30.31, 29.69, 29.62, 29.56, 29.38, 29.36, 29.28, 26.06, 22.68, 14.11. HRMS (ESI positive): $[\mathrm{M}+\mathrm{H}]^{+}$ calcd for $\mathrm{C}_{44} \mathrm{H}_{81} \mathrm{O}_{5} \mathrm{~m} / \mathrm{z}$ 689.60785; found 689.60784. Elemental analysis (EA, \%): calcd for $\mathrm{C}_{44} \mathrm{H}_{80} \mathrm{O}_{5} \mathrm{C}, 76.69 ; \mathrm{H}$, 11.70; found C, 76.74; H, 11.66 .

\section{5-(Chloromethyl)-1,2,3-tris(dodecyloxy)benzene (2)}

A solution of $1(20.00 \mathrm{~g}, 29 \mathrm{mmol})$ in $100 \mathrm{~mL}$ of dry THF was added dropwise to a $50 \mathrm{~mL}$ of $\mathrm{LiAlH}_{4}(2.20 \mathrm{~g}, 58$ mmol) slurry in dry THF at $0{ }^{\circ} \mathrm{C}$. The mixture was then refluxed until 1 was completely exhausted by TLC analysis. The reaction was quenched by dropwise addition of $2.0 \mathrm{~mL}$ of $\mathrm{H}_{2} \mathrm{O}, 2.0 \mathrm{~mL}$ of $15 \% \mathrm{NaOH}$ aqueous solution, and 4.5 $\mathrm{mL}$ of $\mathrm{H}_{2} \mathrm{O}$. A small amount of anhydrous $\mathrm{Na}_{2} \mathrm{SO}_{4}$ was then added to this mixture. The granular salts were filtered and rinsed with THF. After evaporation of the solvent, the crude product was dissolved in $50 \mathrm{~mL}$ of dry DCM with catalytic amounts of DMF. Then $\mathrm{SOCl}_{2}(4.94 \mathrm{~mL}, 60 \mathrm{mmol})$ was added slowly to the solution at $0{ }^{\circ} \mathrm{C}$ in an ice bath. After $30 \mathrm{~min}$, the reaction was completed. The solvent and excess $\mathrm{SOCl}_{2}$ were removed by a rotary evaporator and the crude product was further washed with $50 \mathrm{~mL}$ of $10 \% \mathrm{NaOH}, 50 \mathrm{~mL}$ of $\mathrm{H}_{2} \mathrm{O}$. 5-(chloromethyl)-1,2,3tris(dodecyloxy)benzene was obtained as white solid in yield of 97.5\%. ${ }^{1} \mathbf{H}$ NMR (400 MHz, $\left.\mathrm{CDCl}_{3}, \delta, \mathrm{ppm}\right)$ : 6.57 (s, 2H), 4.51 (s, 2H), 3.98-3.92 (m, 6H), 1.83-1.70 (m, 6H), 1.50-1.42 (m, 6H), 1.39-1.20 (m, 48H), $0.88(\mathrm{t}, J=6.8 \mathrm{~Hz}$, 9H). ${ }^{13}$ C NMR (100 MHz, CDCl3, $\delta$, ppm): 153.19, 138.21, 132.28, 106.98, 73.43, 69.08, 47.01, 31.92, 30.95, 30.31, 29.75, 29.73, 29.70, 29.64, 29.40, 29.37, 26.08, 22.69, 14.13. HRMS (ESI positive): $[\mathrm{M}+\mathrm{H}]^{+}$calcd for $\mathrm{C}_{43} \mathrm{H}_{80} \mathrm{ClO}_{3}$ $\mathrm{m} / \mathrm{z}$ 679.57905; found 679.58073. Elemental analysis (EA, \%): calcd for $\mathrm{C}_{43} \mathrm{H}_{79} \mathrm{ClO}_{3} \mathrm{C}, 76.00 ; \mathrm{H}, 11.72$; found C, $76.08 ; \mathrm{H}, 11.71$.

\section{Methyl 4'-((3,4,5-tris(dodecyloxy)benzyl)oxy)-[1,1'-biphenyl]-4-carboxylate (3)}

Compound 2 (13.00 g, $19 \mathrm{mmol}$ ), methyl 4'-hydroxy-[1,1'-biphenyl]-4-carboxylate (5.25 g, $23 \mathrm{mmol}), \mathrm{K}_{2} \mathrm{CO}_{3}(12.44 \mathrm{~g}$, $90 \mathrm{mmol}$ ), a catalyst amount of potassium iodide (KI) and $250 \mathrm{~mL}$ of acetone were added to a $500 \mathrm{~mL}$ round-bottom flask. The mixture was refluxed overnight. Then the insoluble salt was removed by filtration. The filtrate was evaporated to dryness in vacuo. The crude product was then purified by column chromatography using dichloromethane as the eluent. Methyl 4'-((3,4,5-tris(dodecyloxy)benzyl)oxy)-[1,1'-biphenyl]-4-carboxylate was obtained as white solid in yield of $85.2 \%$. ${ }^{1} \mathbf{H}$ NMR $\left(400 \mathrm{MHz}, \mathrm{CDCl}_{3}, \delta, \mathrm{ppm}\right): 8.08(\mathrm{~d}, J=8.4 \mathrm{~Hz}, 2 \mathrm{H}), 7.62(\mathrm{~d}, J=$ $8.4 \mathrm{~Hz}, 2 \mathrm{H}), 7.58(\mathrm{~d}, J=8.8 \mathrm{~Hz}, 2 \mathrm{H}), 7.07$ (d, $J=8.8 \mathrm{~Hz}, 2 \mathrm{H}), 6.64(\mathrm{~s}, 2 \mathrm{H}), 5.00(\mathrm{~s}, 2 \mathrm{H}), 4.00-3.95(\mathrm{~m}, 6 \mathrm{H}), 3.94(\mathrm{~s}$, $3 \mathrm{H}), 1.83-1.71(\mathrm{~m}, 6 \mathrm{H}), 1.52-1.43(\mathrm{~m}, 6 \mathrm{H}), 1.39-1.20(\mathrm{~m}, 48 \mathrm{H}), 0.88(\mathrm{t}, J=6.8 \mathrm{~Hz}, 9 \mathrm{H}) .{ }^{13} \mathbf{C}$ NMR $(100 \mathrm{MHz}, \mathrm{CDCl}$, $\delta$, ppm): $167.03,159.03,153.32,145.12,137.99,132.62,131.59,130.09,128.34,126.44,115.27,106.11,73.42,70.52$, 69.12, 52.07, 31.91, 30.92, 30.33, 29.75, 29.69, 29.64, 29.41, 29.38, 29.36, 26.09, 22.68, 14.11. HRMS (ESI positive): $[\mathrm{M}+\mathrm{Na}]^{+}$calcd for $\mathrm{C}_{57} \mathrm{H}_{90} \mathrm{NaO}_{6} \mathrm{~m} / \mathrm{z}$ 893.66296; found 893.66163. Elemental analysis (EA, \%): calcd for $\mathrm{C}_{57} \mathrm{H}_{90} \mathrm{O}_{6} \mathrm{C}, 78.57$; H, 10.41; found C, 78.56; H, 10.38 . 


\section{(4'-((3,4,5-Tris(dodecyloxy)benzyl)oxy)-[1,1'-biphenyl]-4-yl)methanol (4)}

A solution of $3(10.00 \mathrm{~g}, 11.5 \mathrm{mmol})$ in $30 \mathrm{~mL}$ of dry THF was added dropwise to a $100 \mathrm{~mL}$ of dry THF and $\mathrm{LiAlH}_{4}$ $(0.76 \mathrm{~g}, 20 \mathrm{mmol})$ slurry at $0{ }^{\circ} \mathrm{C}$. The mixture was refluxed for two hours. The reaction was quenched by dropwise addition of $0.8 \mathrm{~mL}$ of $\mathrm{H}_{2} \mathrm{O}, 0.8 \mathrm{~mL}$ of $15 \% \mathrm{NaOH}$ aqueous solution, and $2.5 \mathrm{~mL}$ of $\mathrm{H}_{2} \mathrm{O}$. A small amount of anhydrous $\mathrm{Na}_{2} \mathrm{SO}_{4}$ was then added to the mixture. The precipitate was filtered and washed with THF. After removing the solvent, the crude product was then purified by column chromatography using dichloromethane/petroleum ether $(1 / 1, \mathrm{v} / \mathrm{v})$ as the eluent. (4'-((3,4,5-Tris(dodecyloxy)benzyl)oxy)-[1,1'-biphenyl]-4-yl)methanol was obtained as white solid in yield of $88.0 \% .{ }^{1} \mathbf{H}$ NMR (400 MHz, $\left.\mathrm{CDCl}_{3}, \delta, \mathrm{ppm}\right): 7.56(\mathrm{~d}, J=8.0 \mathrm{~Hz}, 2 \mathrm{H}), 7.53(\mathrm{~d}, J=8.8 \mathrm{~Hz}, 2 \mathrm{H}), 7.42(\mathrm{~d}, J=8.4 \mathrm{~Hz}$, 2H), 7.05 (d, $J=8.8 \mathrm{~Hz}, 2 \mathrm{H}), 6.64$ (s, 2H), 4.99 (s, 2H), $4.74(\mathrm{~s}, 2 \mathrm{H}), 4.00-3.93(\mathrm{~m}, 6 \mathrm{H}), 1.83-1.71(\mathrm{~m}, 6 \mathrm{H}), 1.51-1.43$ (m, 6H), 1.39-1.20 (m, 48H), 0.88 (t, $J=6.8 \mathrm{~Hz}, 9 \mathrm{H}) .{ }^{13} \mathbf{C} \mathbf{~ N M R}(100 \mathrm{MHz}, \mathrm{CDCl} 3, \delta, \mathrm{ppm}): 158.41,153.29,140.18$, 139.25, 137.90, 133.57, 131.76, 128.08, 127.49, 126.86, 115.14, 106.09, 73.42, 70.52, 69.09, 65.14, 31.92, 30.32, 29.75, 29.74, 29.70, 29.65, 29.41, 29.37, 26.09, 22.69, 14.12. HRMS (ESI positive): $[\mathrm{M}+\mathrm{H}]^{+}$calcd for $\mathrm{C}_{56} \mathrm{H}_{91} \mathrm{O}_{5} \mathrm{~m} / \mathrm{z}$ 843.68610; found 843.68519. Elemental analysis (EA, \%): calcd for $\mathrm{C}_{56} \mathrm{H}_{90} \mathrm{O}_{5} \mathrm{C}, 79.76 ; \mathrm{H}, 10.76$; found C, 79.61; H, 10.67 .

\section{Methyl 4'-((4'-((3,4,5-tris(dodecyloxy)benzyl)oxy)-[1,1'-biphenyl]-4-yl)methoxy)-[1,1'-biphenyl]-4-carboxylate} (5)

A mixture of 4 (9.00 g, $10.7 \mathrm{mmol})$, methyl 4'-hydroxy-[1,1'-biphenyl]-4-carboxylate (4.89 g, $21.4 \mathrm{mmol})$ and triphenylphosphine $(5.62 \mathrm{~g}, 21.4 \mathrm{mmol})$ in anhydrous THF $(100 \mathrm{~mL})$ was added dropwise with a solution of diethyl azodicarboxyate $(3.80 \mathrm{~g}, 21.4 \mathrm{mmol})$ in THF $(10 \mathrm{~mL})$. The mixture was stirred at room temperature for $4 \mathrm{~h}$. After removing the solvent, the crude product was then purified by column chromatography using dichloromethane/petroleum ether $(1 / 1, \mathrm{v} / \mathrm{v})$ as the eluent. Methyl 4'-((4'-((3,4,5-tris(dodecyloxy)benzyl)oxy)-[1,1'biphenyl]-4-yl)methoxy)-[1,1'-biphenyl]-4-carboxylate was obtained as white solid in yield of $75.0 \%$. ${ }^{1} \mathbf{H}$ NMR (400

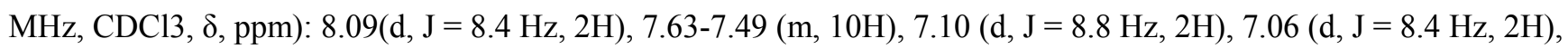
$6.64(\mathrm{~s}, 2 \mathrm{H}), 5.15$ (s, 2H), 4.99 (s, 2H), 4.00-3.94 (m, 6H), 3.93 (s, 3H), 1.83-1.71 (m, 6H), 1.51-1.43 (m, 6H), 1.40$1.20(\mathrm{~m}, 48 \mathrm{H}), 0.88(\mathrm{t}, \mathrm{J}=6.8 \mathrm{~Hz}, 9 \mathrm{H}) .{ }^{13} \mathbf{C}$ NMR $(100 \mathrm{MHz}, \mathrm{CDCl} 3, \delta, \mathrm{ppm}): 167.05,159.03,158.51,153.33,145.15$, $140.62,137.99,135.13,133.50,132.65,131.77,130.11,128.40,128.27,128.13,128.01,126.95,126.47,115.30$, $115.19,106.15,73.44,70.54,69.90,69.13,52.08,31.94,30.36,29.77,29.75,29.72,29.67,29.44,29.41,29.38,26.15$, 26.11, 22.71, 14.14.. HRMS (ESI positive): $[\mathrm{M}+\mathrm{H}]^{+}$calcd for $\mathrm{C}_{70} \mathrm{H}_{101} \mathrm{O}_{7} \mathrm{~m} / \mathrm{z} 1053.75101$; found 1053.75418 Elemental analysis (EA, \%). calcd for $\mathrm{C}_{70} \mathrm{H}_{100} \mathrm{O}_{7}$ : C 79.80; H, 9.57; found: $\mathrm{C} 79.85, \mathrm{H}, 9.67$.

\section{(4'-((4'-((3,4,5-tris(dodecyloxy)benzyl)oxy)-[1,1'-biphenyl]-4-yl)methoxy)-[1,1'-biphenyl]-4-yl)methanol (6)} A solution of $5(5.75 \mathrm{~g}, 5.43 \mathrm{mmol})$ in $30 \mathrm{~mL}$ of dry THF was added dropwise to a $100 \mathrm{~mL}$ of dry THF and $\mathrm{LiAlH}_{4}$

$(0.76 \mathrm{~g}, 20 \mathrm{mmol})$ slurry at $0{ }^{\circ} \mathrm{C}$. The mixture was refluxed for $2 \mathrm{~h}$. The reaction was quenched by dropwise addition of $0.8 \mathrm{~mL}$ of $\mathrm{H}_{2} \mathrm{O}, 0.8 \mathrm{~mL}$ of $15 \% \mathrm{NaOH}$ aqueous solution, and $2.5 \mathrm{~mL}$ of $\mathrm{H}_{2} \mathrm{O}$. A small amount of anhydrous $\mathrm{Na}_{2} \mathrm{SO}_{4}$ was then added to the mixture. The precipitate was filtered and washed with THF. After removing the solvent, the crude product was then purified by column chromatography using dichloromethane/petroleum ether $(1 / 1, \mathrm{v} / \mathrm{v})$ as the eluent. (4'-(4'-((4'-((3,4,5-tris(dodecyloxy)benzyl)oxy)-[1,1'-biphenyl]-4-yl)methoxy)-[1,1'-biphenyl]-4-yl)methanol was obtained as white solid in yield of $92.0 \% .{ }^{1} \mathbf{H}$ NMR (400 MHz, $\left.\mathrm{CDCl}_{3}, \delta, \mathrm{ppm}\right): 1 \mathrm{H} \mathrm{NMR}(400 \mathrm{MHz}, \mathrm{CDCl} 3, \delta$, ppm): 7.60-7.50 (m, 10H), 7.43 (d, J = 8.4 Hz, 2H), 7.09 (d, J = 7.2 Hz, 2H), 7.06 (d, J = 7.2 Hz, 2H), 6.65(s, 2H), 5.14 (s, 2H), 4.99 (s, 2H), 4.74 (s, 2H), 4.00-3.94 (m, 6H), 1.83- $1.71(\mathrm{~m}, 6 \mathrm{H}), 1.51-1.43(\mathrm{~m}, 6 \mathrm{H}), 1.40-1.20(\mathrm{~m}, 48 \mathrm{H})$, 
$0.88(\mathrm{t}, \mathrm{J}=6.8 \mathrm{~Hz}, 9 \mathrm{H}) .{ }^{13} \mathbf{C}$ NMR (100 MHz, CDCl3, $\left.\delta, \mathrm{ppm}\right): 158.49,158.42,153.32,140.56,140.20,139.29,137.97$, $135.31,133.61,133.54,131.78,128.13,128.01,127.49,126.93,126.88,115.16,106.14,73.44,70.54,69.89,69.13$, $65.15,31.94,30.35,29.77,29.75,29.72,29.67,29.44,29.41,29.38,26.15,26.11,22.71,14.14 .$. HRMS (ESI positive) $\mathrm{m} / z$ : $\left[\mathrm{M}+\mathrm{NH}_{4}\right]^{+}$calcd for $\mathrm{C}_{69} \mathrm{H}_{104} \mathrm{NO}_{6}, 1042.78415$; found, 1042.78582. Elemental analysis (EA, \%). calcd for $\mathrm{C}_{69} \mathrm{H}_{100} \mathrm{O}_{6}$ : C 80.81; H, 9.83; found: C 80.79, H, 9.97 .

\section{(4'-((4'-((3,4,5-tris(dodecyloxy)benzyl)oxy)-[1,1'-biphenyl]-4-yl)methoxy)-[1,1'-biphenyl]-4-yl)methyl}

\section{(1R,2S,4R)-bicyclo[2.2.1] hept-5-ene-2-carboxylate (M1)}

To a solution of 6 (5.56 g, $6.6 \mathrm{mmol})$, exo-5-norbornenecarboxylic acid ( $0.83 \mathrm{~g}, 6 \mathrm{mmol})$ and 4-dimethylaminopyridine (DMAP, $0.16 \mathrm{~g}, 1.32 \mathrm{mmol}$ ) in $100 \mathrm{~mL}$ of dry DCM, was added N,N'-dicyclohexylcarbodiimide (DCC, $2.72 \mathrm{~g}, 13.2$ $\mathrm{mmol}$ ) under the ice bath, and the mixture was stirred at room temperature for $24 \mathrm{~h}$. The reaction mixture was then filtered to remove the insoluble salt. After evaporation of the solvent, the crude product was purified by column chromatography using dichloromethane/ petroleum ether $(3 / 4, v / v)$ as the eluent. The monomer M1 was obtained as white solid in yield of 70.5\%. ${ }^{1} \mathbf{H}$ NMR (400 MHz, $\mathrm{CDCl}_{3}, \delta$, ppm): 7.60-7.50 (m, 10H), $7.42(\mathrm{~d}, J=8.4 \mathrm{~Hz}, 2 \mathrm{H}), 7.09$ (d, $J=7.2 \mathrm{~Hz}, 2 \mathrm{H}), 7.06$ (d, $J=7.6 \mathrm{~Hz}, 2 \mathrm{H}), 6.64(\mathrm{~s}, 2 \mathrm{H}), 6.16-6.10(\mathrm{~m}, 2 \mathrm{H}), 5.16(\mathrm{~s}, 2 \mathrm{H}), 5.14(\mathrm{~s}, 2 \mathrm{H}), 4.99(\mathrm{~s}, 2 \mathrm{H})$, 4.00-3.94 (m, 6H), 3.09 (s, 1H), $2.94(\mathrm{~s}, 1 \mathrm{H}), 2.30(\mathrm{~m}, 1 \mathrm{H}), 1.97(\mathrm{~m}, 1 \mathrm{H}), 1.83-1.71(\mathrm{~m}, 6 \mathrm{H}), 1.55(\mathrm{~s}, 1 \mathrm{H}), 1.51-1.43$ (m, 6H), 1.40-1.20 (m, 50H), 0.88(t, $J=6.8 \mathrm{~Hz}, 9 \mathrm{H}) ;{ }^{13} \mathbf{C}$ NMR (100 MHz, $\left.\mathrm{CDCl}_{3}, \delta, \mathrm{ppm}\right): 176.12,158.50,153.33$, $140.69,140.57,138.10,137.99,135.73,135.29,134.63,133.53,133.46,131.77,128.64,128.17,128.13,128.01$, $126.94,126.87,115.18,106.15,73.43,70.54,69.89,69.13,66.07,46.66,46.38,43.19,41.66,31.94,30.40,30.35$, 29.77, 29.72, 29.66, 29.43, 29.41, 29.38, 26.15, 26.11, 22.70, 14.13. HRMS (ESI positive) $\mathrm{m} / z$ : $[\mathrm{M}+\mathrm{Na}]^{+}$calcd for $\mathrm{C}_{77} \mathrm{H}_{108} \mathrm{NaO}_{7}, 1167.84333$; found, 1167.84087. Elemental analysis (EA, \%). calcd for $\mathrm{C}_{77} \mathrm{H}_{108} \mathrm{O}_{7}$ : C 80.72, H 9.50; found: C $80.58, \mathrm{H} 9.60$.

\section{Polymerization of M1}

M1 (200 mg, $0.175 \mathrm{mmol})$ and Grubbs third-generation catalyst $\left(0.77 \mathrm{mg}, 8.7 \times 10^{-4} \mathrm{mmol}\right.$ for $\mathbf{P} \mathbf{1}_{\mathbf{H}} ; 0.15 \mathrm{mg}, 1.7 \times 10^{-4}$ mmol for $\mathbf{P} \mathbf{1}_{\mathbf{L}}$ ) were loaded in a dry Schlenk tube with a magnetic stirring bar. After three pump-purge cycles with high purity nitrogen, $2 \mathrm{~mL}$ of dry DCM was injected to the mixture under vigorous stirring to initiate polymerization. After the reaction mixture was stirred at room temperature for $2 \mathrm{~h}$, a few drops of vinyl ethyl ether were added to the reaction mixture using a syringe to quench the polymerization. The viscous liquid was diluted with $5 \mathrm{~mL}$ of DCM and passed through a short alumina column to remove the catalyst, and then the polymer solution was added dropwise to $100 \mathrm{~mL}$ of methanol under stirring. The dissolution and precipitation process were repeated three times. The resulting polymer was precipitated out, collected by centrifugation, and dried under vacuum to a constant weight. P1 was obtained as white solid in yield of 91.5\%. ${ }^{1} \mathbf{H}$ NMR (400 MHz, $\left.\mathrm{CDCl}_{3}, \delta, \mathrm{ppm}\right): 7.48$ (br, 10H), 7.32 (br, 2H), 7.00 (br, 4H), $6.61(\mathrm{~s}, 2 \mathrm{H}), 5.28(\mathrm{br}, 2 \mathrm{H}), 5.08(\mathrm{br}, 2 \mathrm{H}), 5.02(\mathrm{br}, 2 \mathrm{H}) 4.93(\mathrm{~s}, 2 \mathrm{H}), 3.95(\mathrm{~m}, 6 \mathrm{H}), 3.02(\mathrm{br}, 1 \mathrm{H}), 2.55(\mathrm{br}, 2 \mathrm{H})$, $2.08(\mathrm{br}, 1 \mathrm{H}), 1.77(\mathrm{~m}, 6 \mathrm{H}), 1.45(\mathrm{~m}, 7 \mathrm{H}), 1.25(\mathrm{br}, 50 \mathrm{H}), 0.87(\mathrm{~m}, 9 \mathrm{H}) . \boldsymbol{M}_{\mathbf{w}}\left(\mathbf{P} \mathbf{1}_{\mathrm{H}}\right)=420000(\mathrm{SLS}$ result $), \boldsymbol{M}_{\mathrm{w}} / \boldsymbol{M}_{\mathbf{n}}=1.3$ (GPC result). $\boldsymbol{M}_{\mathrm{w}}\left(\mathbf{P} 1_{\mathrm{L}}\right)=33000$ (SLS result), $\boldsymbol{M}_{\mathrm{w}} / \boldsymbol{M}_{\mathbf{n}}=1.1$ (GPC result).

\section{Preparing of film samples}

Thin films of $\mathbf{P} 1$ were obtained by spin coating on silicon substrates with toluene solution of $\mathbf{P} \mathbf{1}_{\mathbf{H}}$ or $\mathbf{P} \mathbf{1}_{\mathbf{L}}$. The concentration of polymer solutions is $10 \mathrm{mg} / \mathrm{mL}$, the rotate speed is $1000 \mathrm{rad} / \mathrm{s}$. All the prepared samples were dried at room temperature for $24 \mathrm{~h}$ before annealing. 
NMR spectrum of M1 and P1<smiles></smiles>

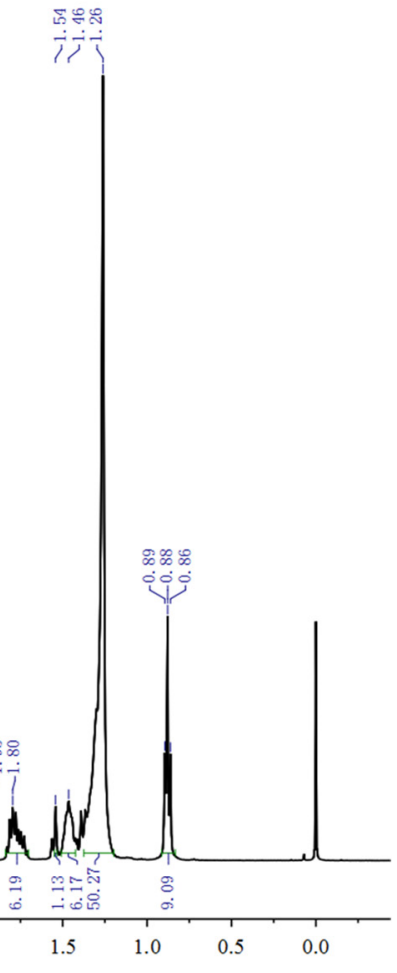

${ }^{\mathrm{M} 1}{ }^{13} \mathrm{C}$

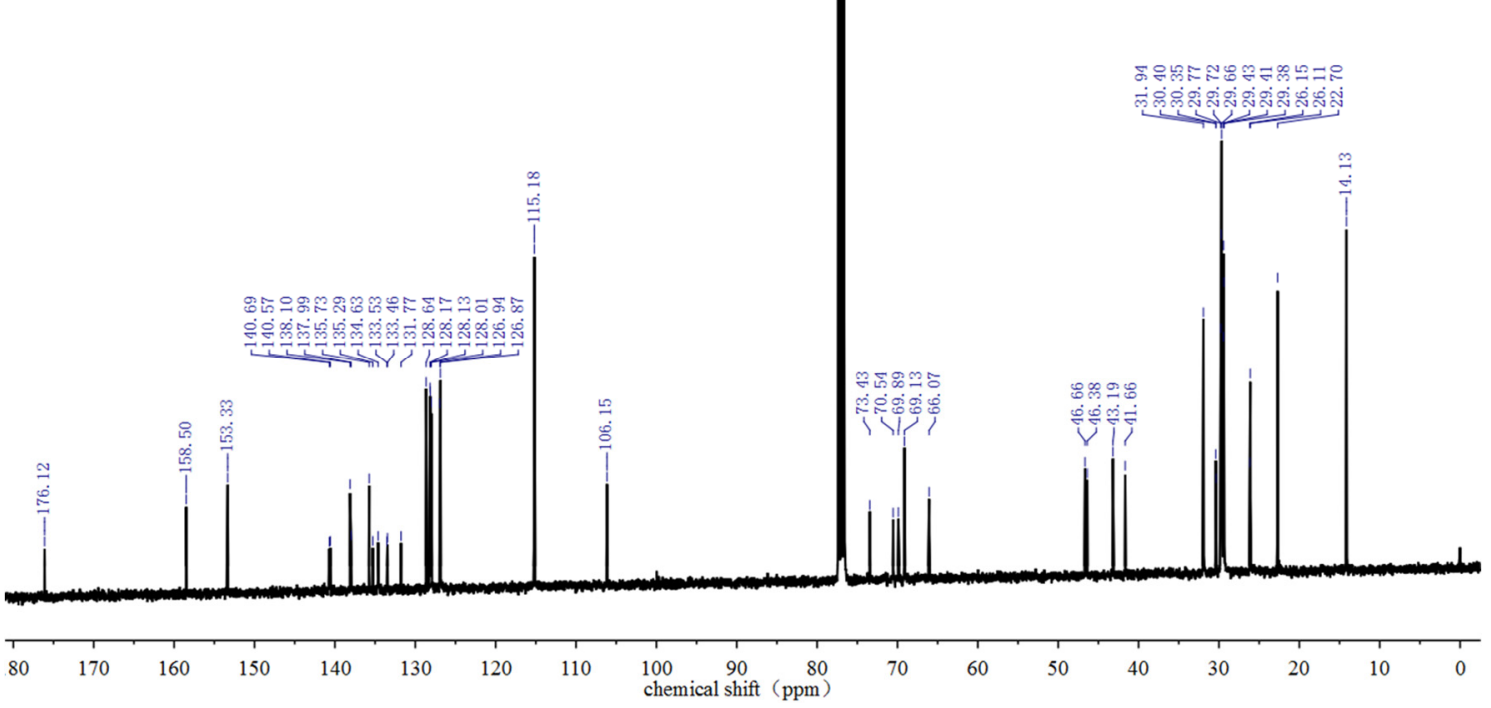




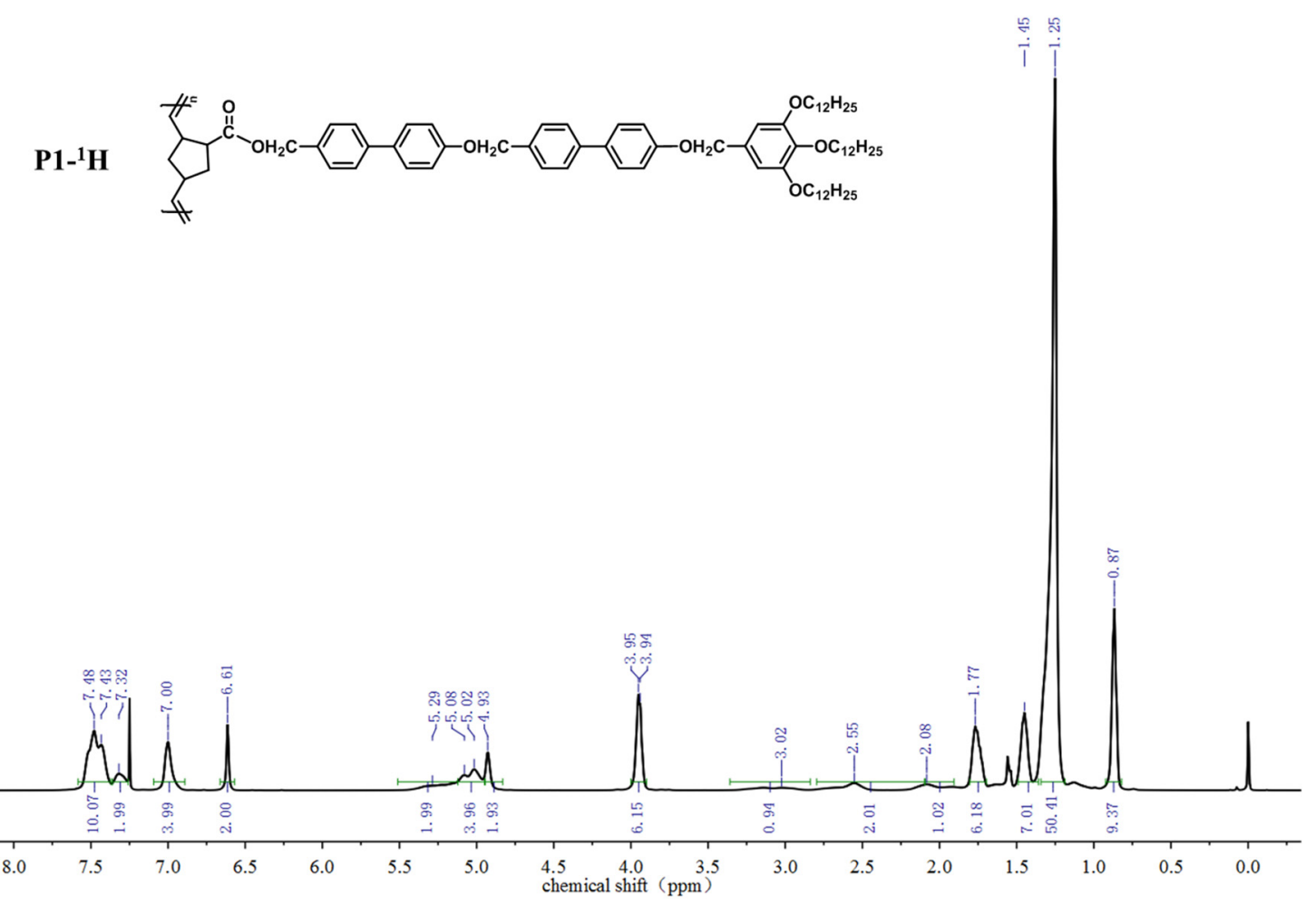




\section{Instruments and Measurements}

${ }^{1} \mathrm{H}$ NMR (400 MHz) and ${ }^{13} \mathrm{C}$ NMR (100 MHz) spectra were recorded using a Bruker ARX400 spectrometer at room temperature using deuterated chloroform $\left(\mathrm{CDCl}_{3}\right)$ as the solvent and tetramethylsilane (TMS) as the internal standard. Elemental analysis was performed with an Elementar Vario EL instrument. Mass spectra were recorded on a Bruker APEX IV mass spectrometer.

A TA Q100 instrument was used under a nitrogen atmosphere. The samples with a typical mass of 3-5 mg were encapsulated in hermetically sealed aluminum pans. Temperature was set from -50 to $230^{\circ} \mathrm{C}$ with an increasing rate at $10.0^{\circ} \mathrm{C} / \mathrm{min}$. The DSC traces in Figure 2a represent the second heating process.

1D, 2D and grazing-incidence (GI) XRD were performed with Ganesha system (SAXSLAB, U.S.) equipped with a multilayer focused $\mathrm{Cu} \mathrm{K} \alpha$ radiation as the X-ray source (Genix3D Cu ULD) and a two-dimensional semiconductor detector (Pilatus $100 \mathrm{~K}$, DECTRIS, Swiss). The scattering peak positions were calibrated with $\mathrm{LaB}_{6}$ for wide-angle region and silver behenate for small-angle region, respectively. A Linkam HFSX350-GI stage was utilized to study the structure evolution as a function of temperature. And the distance between the sample and the detector is $1050 \mathrm{~mm}$. GI-XRD experiment of the large-area oriented sample (Figure. 6) was performed at the Beamline BL16B1 of the Shanghai Synchrotron Radiation Facility (SSRF). The X-ray wavelength $(\lambda)$ was $1.2398 \AA$. The sample-to-detector distance was $1900 \mathrm{~mm}$. The incident angle is 0.3 degree, which is larger than the measured critical angle of P1 (0.2 degree). The data was collected by a Mar165 detector, and calibrated by silver behenate powder. The 1D-diffraction of the GI-XRD pattern (Fig. 6-d) is the azimuthal integration, which was performed with Fit 2D software.

Dimension Icon atomic force microscopy (AFM, Bruker Nano) was used at room temperature. PeakForce tapping mode was applied in the experiments using SCANASYST-AIR probes (tip radius: $\sim 2 \mathrm{~nm}$; spring 205 constant: $\sim 0.4$ $\mathrm{N} / \mathrm{m}$; frequency: $\sim 70 \mathrm{kHz}$ ).

Gel permeation chromatography (GPC) was carried out on a Waters 515 GPC instrument using THF as an eluent at a flow rate of $1.0 \mathrm{~mL} / \mathrm{min}$ at $35^{\circ} \mathrm{C}$. The GPC calibration curve was obtained with linear polystyrene standards.

Both static light scattering (SLS) and dynamic light scattering (DLS) were performed using a commercialized spectrometer from Brookhaven Instrument Corporation (BI-200SM Goniometer, Holtsville, NY). A vertically polarized, $17 \mathrm{~mW}$ He-Ne laser (Research Electro-Optics, Inc., Boulder, $\mathrm{CO}$ ) operating at $633 \mathrm{~nm}$ was used as the light source.

Rheology temperature sweep measurements were carried out on a TA ARES-G2 rheometer with $8 \mathrm{~mm}$ parallel plate and approximately $1 \mathrm{~mm}$ gap under nitrogen flow over a temperature range from 30 to $200^{\circ} \mathrm{C}$. The heating rate is $5{ }^{\circ} \mathrm{C} / \mathrm{min}$. The sample was measured in the small-amplitude oscillatory shear mode with a constant frequency of 1 $\mathrm{rad} / \mathrm{s}$ and oscillation strain of $1 \%$. 


\section{Solution Light Scattering}

\section{Static solution light scattering (SLS)}

Angular dependence of the excess absolute time averaged scattered intensity of dilute polymer solution, known as the Rayleigh ratio $R_{\mathrm{vv}}(\theta)$, was measured by SLS. The weight-averaged molar mass $\left(M_{\mathrm{w}}\right)$ and the root-mean-square radius of gyration $\left(R_{\mathrm{g}}\right)$ can be obtained based on the following equations:

$$
\frac{K_{c}}{R_{V V}(\theta)}=\frac{1}{M_{w}}\left(1+\frac{1}{3} q^{2} R_{g}^{2}\right)+2 A_{2} c
$$

with $\mathrm{K}=\frac{4 \pi^{2} n^{2}(d n / d c)^{2}}{N_{A} \lambda^{4}}$ and $\mathrm{q}=\frac{4 \pi n \sin (\theta / 2)}{\lambda}$, wherein $N_{\mathrm{A}}, n, \mathrm{~d} n / \mathrm{d} c$, and $\lambda$ are the Avogadro's number, solvent refractive index, specific refractive index increment, and the wavelength of light in a vacuum, respectively.

The persistence length $L_{\mathrm{P}}$ can be obtained with the following equation:

$$
R_{g}{ }^{2}=\frac{1}{3} L_{P} L_{C}-L_{P}{ }^{2}+2 \frac{L_{P}{ }^{3}}{L_{C}}\left(1-\frac{L_{P}}{L_{C}}\left[1-\exp \left(-\frac{L_{P}}{L_{C}}\right)\right]\right)
$$

where $L_{\mathrm{C}}$ is the contour length of polymer chain.

\section{Dynamic solution light scattering (SLS)}

The intensity-intensity time correlation function $G^{(2)}(\tau)$ in the self-beating mode was measured by dynamic light scattering (DLS). A Laplace inversion program, CONTIN, was used to process the data to obtain the line width distribution and diffusion coefficient. The diffusion coefficient $\mathrm{D}$ can be further converted into the hydrodynamic radius $R_{\mathrm{h}}$ by using the Stokes-Einstein equation:

$$
\mathrm{D}=k_{B} T / 6 \pi \eta R_{h}
$$

where $k_{\mathrm{B}}, T$, and $\eta$ are the Boltzmann constant, the absolute temperature, and the viscosity of the solvent, respectively. 


\section{Molecular Mechanics Simulation on $\mathbf{P} 1^{[2]}$}

Molecular mechanics simulation was performed using Materials Studio software package 8.0 (Accelrys Software Inc.). Single chains of $\mathbf{P 1}$ were built by 20 repeating units through head-to-tail arrangement with various connecting dihedral angles. The initial dihedral angles were chosen in the range of $0^{\circ}-180^{\circ}$, leading the chain conformation to change from fully compressed to fully extended. Geometry optimization of the single chain was carried out through the Forcite module with the Condensed-phase Optimized Molecular Potentials for Atomistic Simulation Studies (COMPASS) force field. The convergence level for optimization was set to be ultrafine. After geometry optimization, the total chain lengths (20 repeating units) were measured, from which the average projection length of one repeating unit on the chain axis was calculated. Snapshots of single chains of $\mathbf{P 1}$ with 20 repeating units at different dihedral angles after geometry optimization are shown in Figure S6.

\section{Reconstruction of relative electron density map (EDM) of $M 1$ and $P 1^{[1,3]}$}

On the basis of XRD data, the reconstruction of relative electron density distribution of M1 in real space is carried out using the formula for three-dimensional (3D) Fourier transformation:

$$
\rho(x, y, z)-\rho_{0}=\sum_{h k l} F(h k l) \exp [i 2 \pi(h x+k y+l z)]
$$

where $\rho$ is the average electron density and $x, y$ and $z$ are the fractional coordinates of a point in the unit cell. $F(h k l)$ is the complex structure factor and its modulus is related to the diffraction intensities $I(h k l)$ by $|F(h k l)|=\sqrt{I(h k l)}$. Note that diffraction intensities need to be multiplicity corrected. Also the summation is executed over all possible integer combination of $(h k l)$ except for $(000)$.

If the lattice is chosen as centrosymmetric, the structure factor becomes real and is given by $F(h k l)= \pm|F(h k l)|$, with corresponding possible phase of $0(+)$ or $\pi(-)$. Then the electron density can be expressed as:

$$
\rho(x, y, z)-\rho_{0}=\sum_{h k l} \pm \sqrt{I(h k l)} \cos [i 2 \pi(h x+k y+l z)]
$$

The EDMs were calculated using the suitable phase combinations for the corresponding reflections. Relative integrated intensities, experimental and calculated $d$-spacings, and phases used in the reconstruction of electron densities for the $\mathrm{Cub} / \mathrm{Im} \overline{3} m$ phase of $\mathbf{M} 1$ at $50{ }^{\circ} \mathrm{C}$ is listed in the Table S1.

If we consider a two-dimensional (2D) electron density distribution, then the third component $z$ is absent and all calculations are performed in $(x, y)$ space. In Figure. 3(a) we give the 2D relative electron density of $\mathbf{P 1}$ since it is a hexagonal columnar phase. 


\section{Figures and Tables}
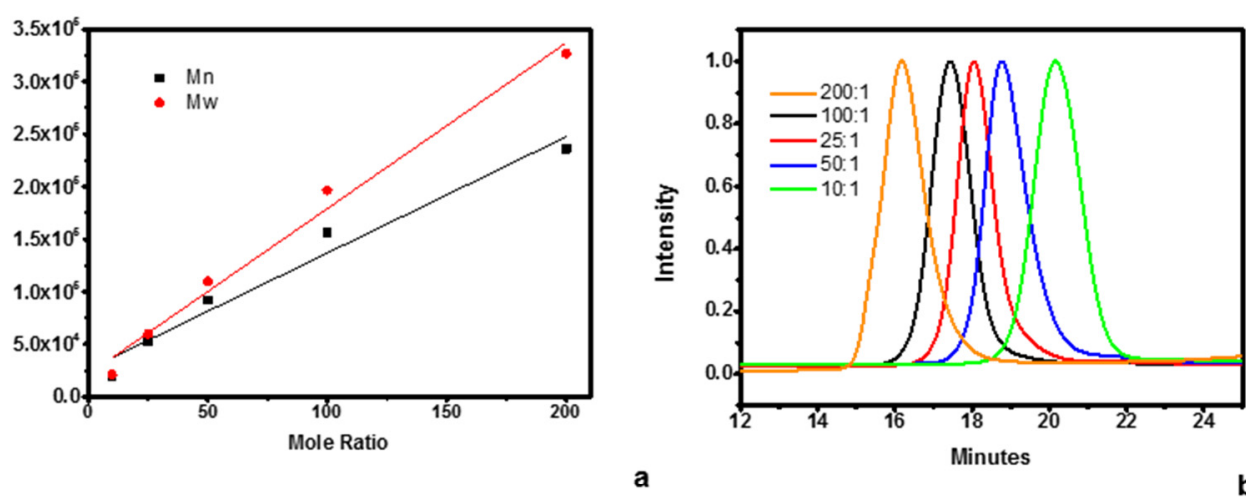

\begin{tabular}{cccc}
\hline $\begin{array}{c}\text { Mole ratio } \\
\text { (M1:Cat) }\end{array}$ & $\begin{array}{c}M_{\mathrm{n}} \\
(\mathrm{g} / \mathrm{mol})\end{array}$ & $\begin{array}{c}M_{\mathrm{w}} \\
(\mathrm{g} / \mathrm{mol})\end{array}$ & PDI \\
\hline $10: 1$ & 19500 & $21800\left(33000^{*}\right)$ & 1.09 \\
$25: 1$ & 52700 & 59700 & 1.13 \\
$50: 1$ & 91900 & 109900 & 1.20 \\
$100: 1$ & 156400 & 196500 & 1.22 \\
$200: 1$ & 236100 & $326600\left(420000^{*}\right)$ & 1.25 \\
\hline
\end{tabular}

Figure S1. GPC result of P1 samples obtained by ROMP method with different mole ratios between M1 and

Grubbs $3^{\text {rd }}$ catalyst. (a) GPC curves of P1 samples with different molecular weights; (b) Linear correlation between the mole ratio and the molecular weight. The table lists the number- and weight-average molecular weight $\left(M_{\mathrm{n}}\right.$ and $M_{\mathrm{w}}$ ) of the $\mathbf{P 1}$ samples measured by GPC calibrated using polystyrene standards. 

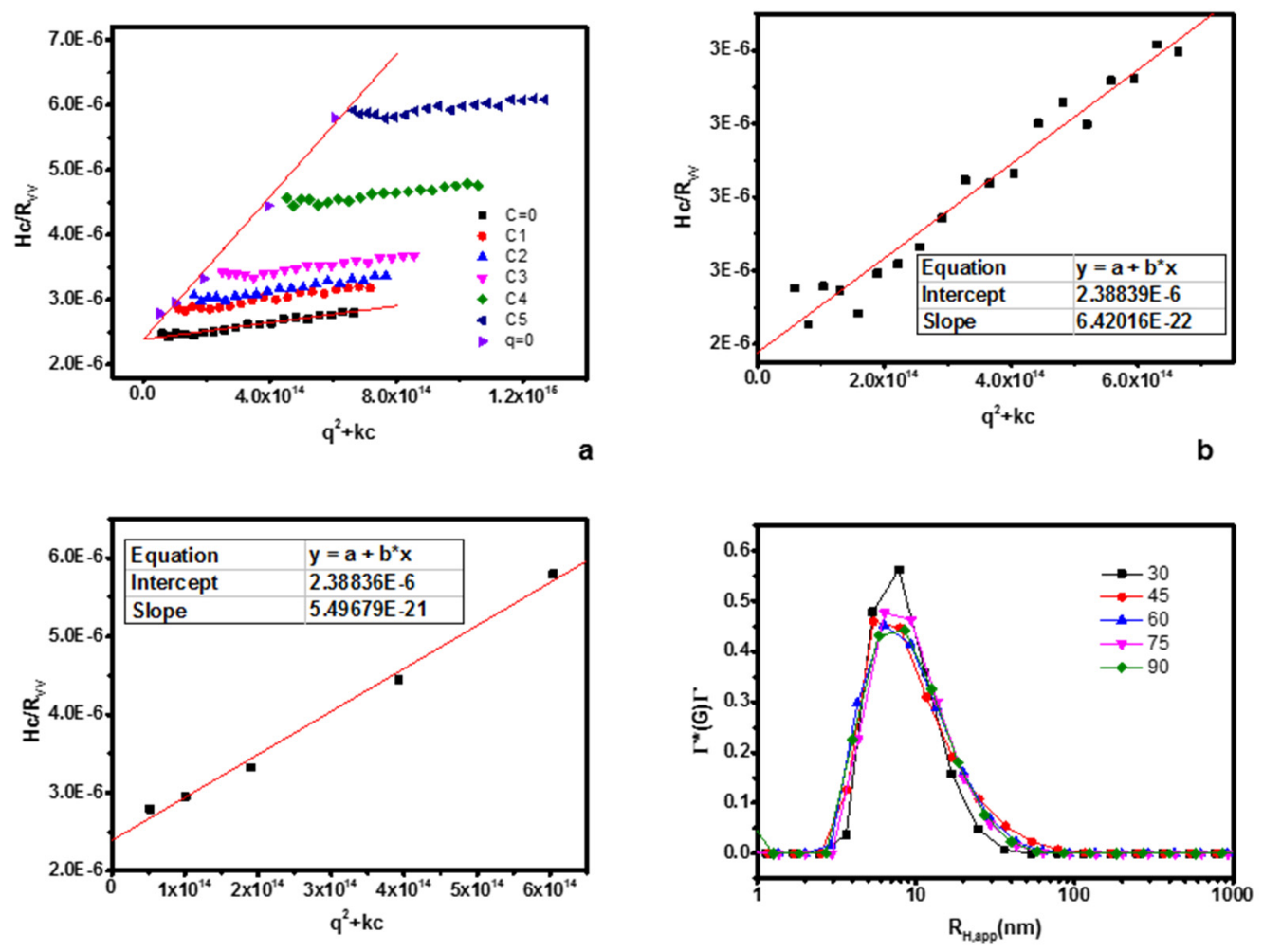

d

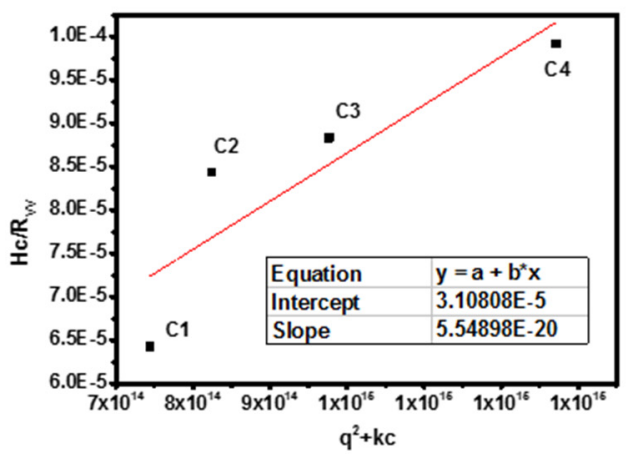

\begin{tabular}{ccc}
\hline Sample & $\mathbf{P 1} 1_{\mathrm{H}}$ & $\mathbf{P} 1_{\mathrm{L}}$ \\
\hline $\mathrm{d} n / \mathrm{d} c$ & 0.096 & 0.097 \\
$\boldsymbol{M}_{\mathrm{w}}$ & 420000 & 33000 \\
$\boldsymbol{R}_{\mathrm{g}}$ & $29 \mathrm{~nm}$ & - \\
$\boldsymbol{R}_{\mathrm{h}}$ & $15 \mathrm{~nm}$ & - \\
$L_{\mathrm{P}}$ & \multicolumn{2}{c}{$18 \mathrm{~nm}$} \\
\hline
\end{tabular}

Figure S2: Solution light scattering results of $\mathbf{P} 1_{\mathbf{H}}$ and $\mathbf{P} \mathbf{1}_{\mathbf{L}}$. (a) Zimm-plot of $\mathbf{P} \mathbf{1}_{\mathbf{H}}$ solution with different concentration $(\mathrm{C} 1=0.52, \mathrm{C} 2=1.01, \mathrm{C} 3=1.90, \mathrm{C} 4=3.93, \mathrm{C} 5=6.04 \mathrm{mg} / \mathrm{mL})$. (b) Angular dependence of $R_{\mathrm{vv}}(\theta)$ of $\mathbf{P} \mathbf{1}_{\mathbf{H}}$ solution when extrapolating concentration to zero. (c) Concentration dependence of $R_{\mathrm{Vv}}(\theta)$ of $\mathbf{P} \mathbf{1}_{\mathbf{H}}$ solution when extrapolating $q$ to zero. (d) Distribution of hydrodynamic radius $\left(R_{\mathrm{h}}\right)$ of $\mathbf{P} \mathbf{1}_{\mathbf{H}}$ measured at different angle using dynamic light scattering. (e) $R_{\mathrm{vv}}\left(90^{\circ}\right)$ of $\mathbf{P} \mathbf{1}_{\mathbf{L}}$ solution with different concentration $(\mathrm{C} 1=0.80, \mathrm{C} 2=1.60, \mathrm{C} 3=3.12, \mathrm{C} 4=6.07$ $\mathrm{mg} / \mathrm{mL}$ ). (f) Measured specific refractive index increment $(\mathrm{d} n / \mathrm{d} c)$ of $\mathbf{P} \mathbf{1}_{\mathbf{H}}$ and $\mathbf{P} \mathbf{1}_{\mathbf{L}}$ solution, calculated weight-averaged molar mass $\left(M_{\mathrm{w}}\right)$, root-mean-square radius of gyration $\left(R_{\mathrm{g}}\right)$, hydrodynamic radius $\left(R_{\mathrm{h}}\right)$ and persistence length $\left(L_{\mathrm{P}}\right)$ of $\mathbf{P} \mathbf{1}_{\mathbf{H}}$ and $\mathbf{P} \mathbf{1}_{\mathbf{L}}$ in dilute solution ${ }^{[4,5]}$. The ratio of $R_{\mathrm{g}} / R_{\mathrm{h}}$ is $\sim 1.9$, indicating that the $\mathbf{P 1}$ chain is ellipsoid-like rather than random coil in solution. Solvent: toluene. 


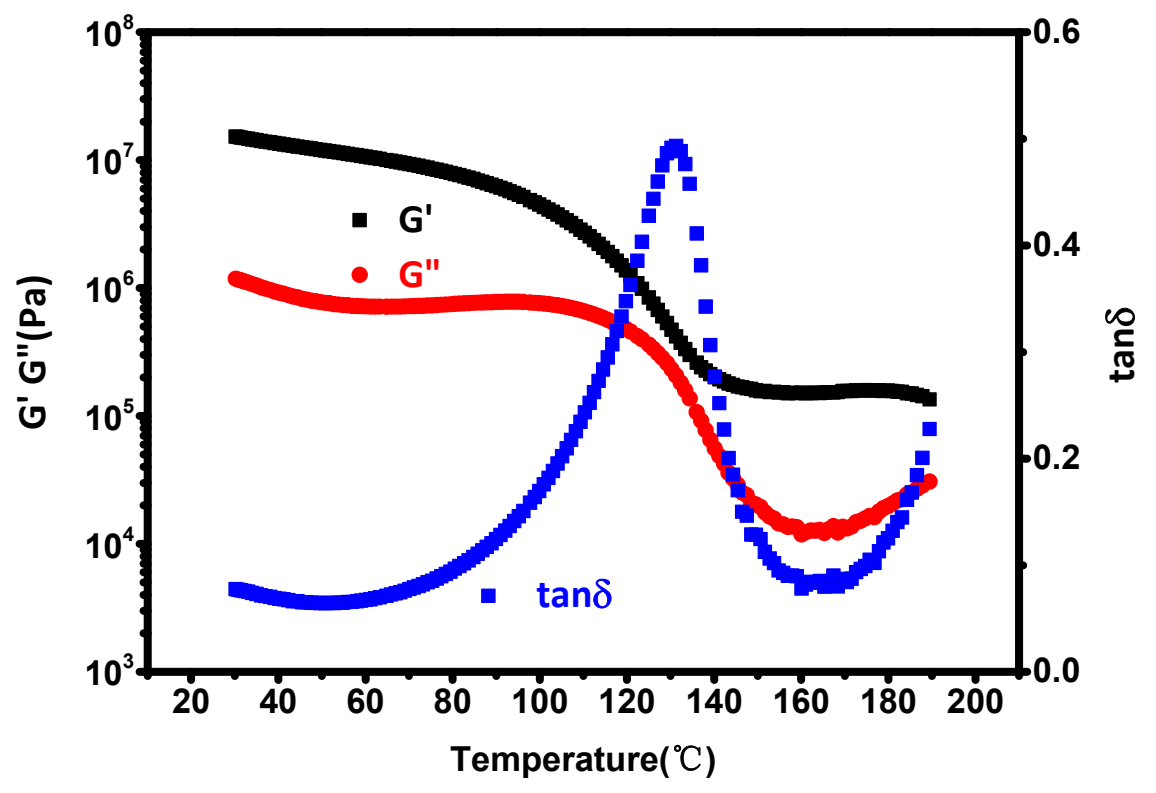

Figure S3. Rheology temperature sweep result of $\mathbf{P} 1_{\mathrm{H}}$.
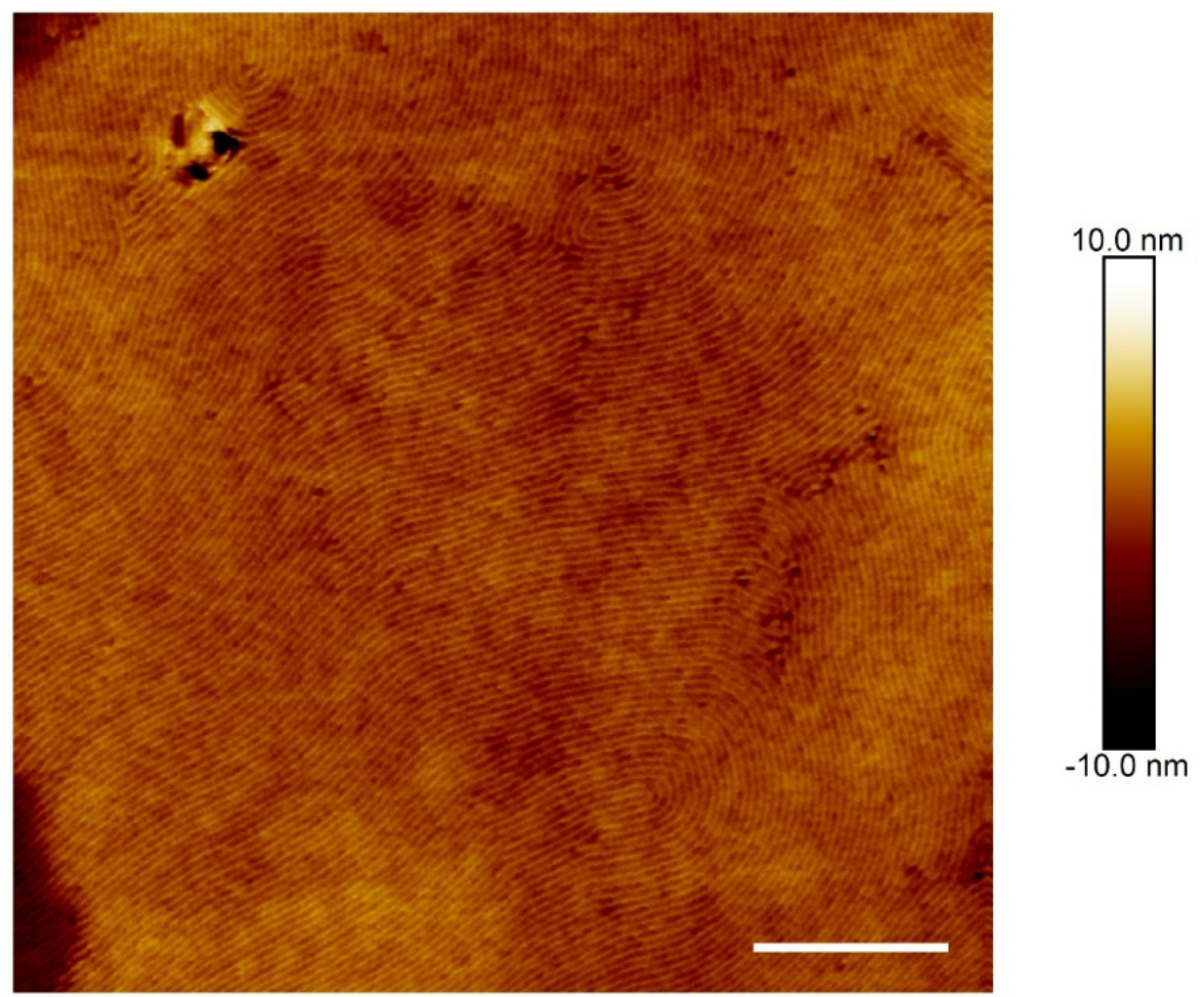

Figure S4. AFM result of $\mathbf{P 1}_{\mathbf{H}}$ after annealing at $200{ }^{\circ} \mathrm{C}$. Columns in the image have the length longer than $1 \mu \mathrm{m}$. Scale bar: $200 \mathrm{~nm}$. 

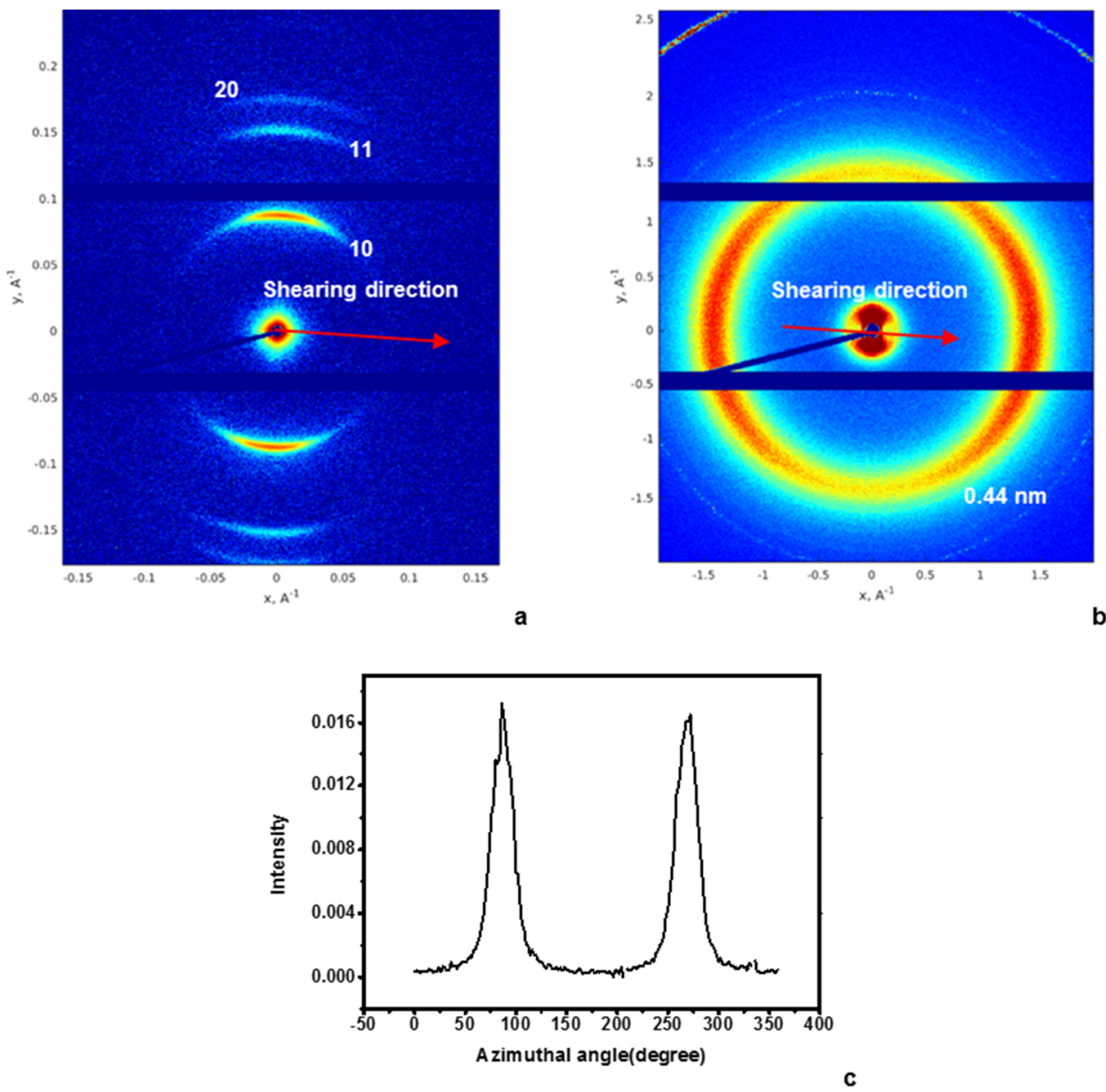

Figure S5. Two-dimensional (2D) XRD results of $P 1_{H}$ oriented by mechanical shearing. (a) small-angle region, (b) wide-angle region, (c) Azimuthal scanning data of the (10) diffraction in (a). The Hermans-Stein orientation factor $f_{10}$ was calculated with the following equation:

$$
\begin{gathered}
f_{10}=\frac{3<\cos ^{2} \emptyset_{10}>-1}{2} \\
<\cos ^{2} \emptyset_{10}>=\frac{\int_{0}^{\frac{\pi}{2}} I(\varnothing) \sin \emptyset \cos ^{2} \emptyset d \emptyset}{\int_{0}^{\frac{\pi}{2}} I(\emptyset) \sin \emptyset d \emptyset}
\end{gathered}
$$

where $\Phi$ is the azimuthal angle of the meridional diffraction, $I(\Phi)$ is the intensity. 

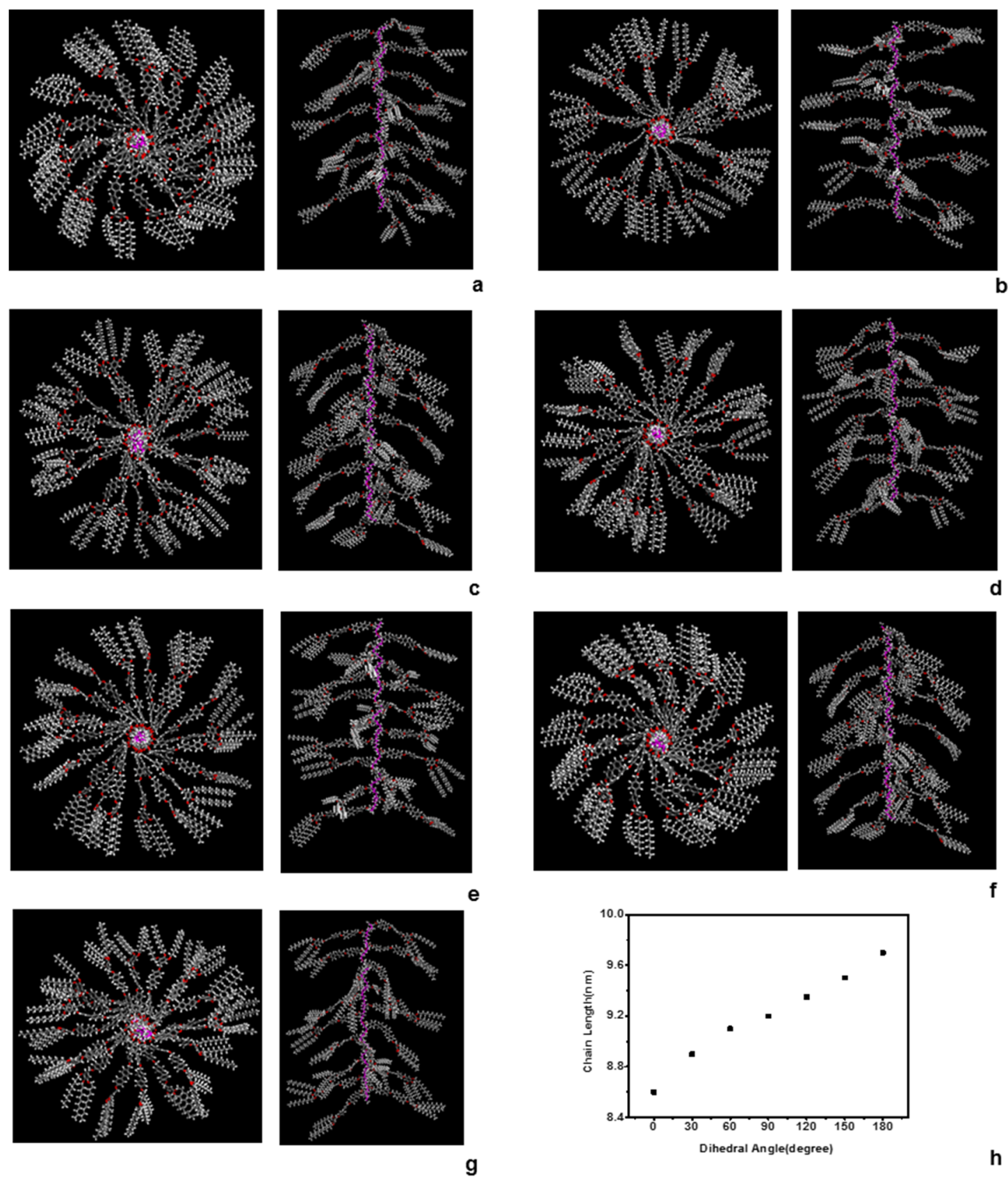

h

Figure S6. Molecular Models of single chains of P1 containing 20 repeating units with different initial dihedral angles after geometry optimization. (a) $0^{\circ}$, (b) $30^{\circ}$, (c) $60^{\circ}$, (d) $90^{\circ}$, (e) $120^{\circ}$, (f) $150^{\circ}$, (g) $180^{\circ}$ (Left: top view; right: front view), and (h) Dependence of $\mathbf{P 1}$ chain length on the initial dihedral angles. The chain conformation transforms from fully compressed to fully extended when the dihedral angles change from $0^{\circ}$ to $180^{\circ}$. Nevertheless, the projection of one repeating unit on the polynorbornene chain axis only varies a little bit, which is in the range of $0.43-0.48 \mathrm{~nm}$. 


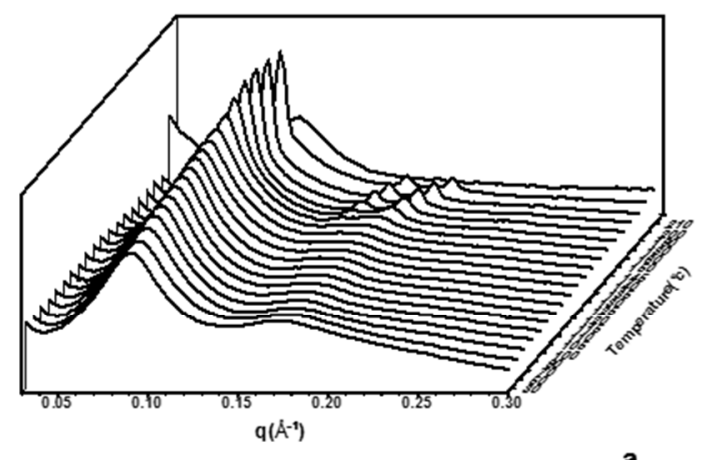

a

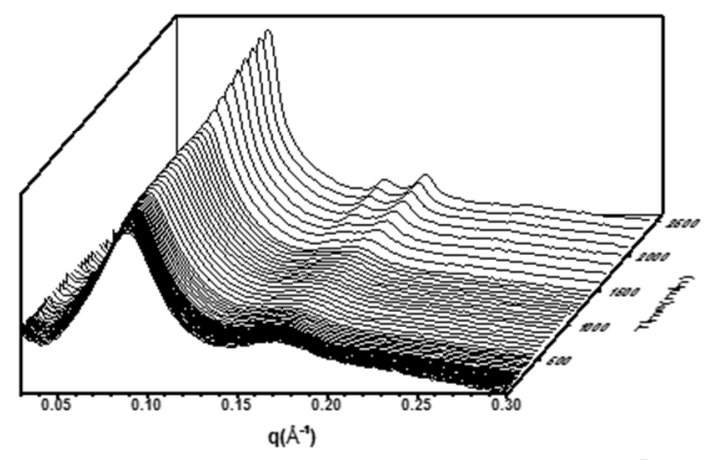

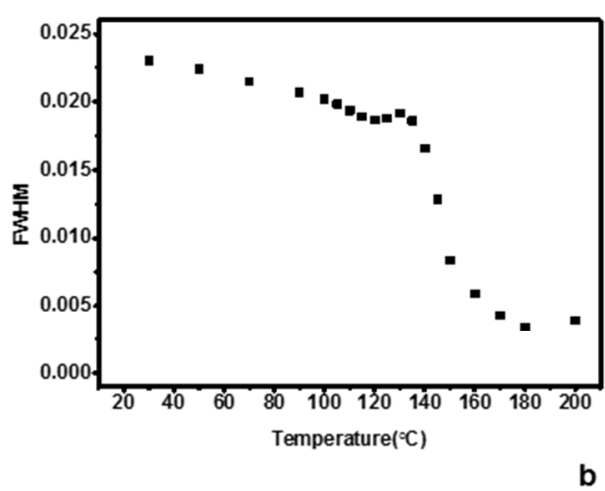

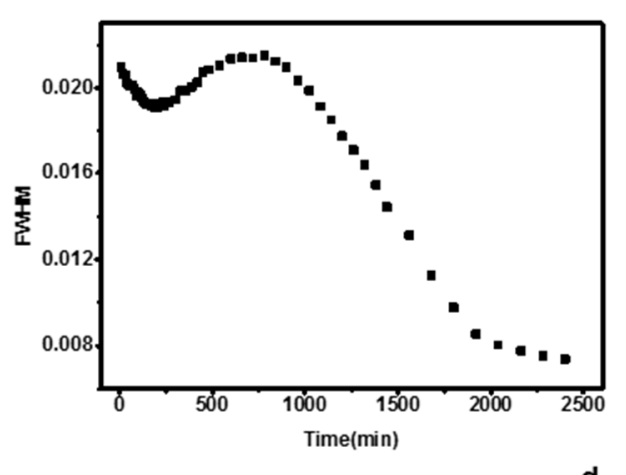

Figure S7. Phase transition of $\mathbf{P} \mathbf{1}_{\mathbf{H}}$. (a) 1D XRD profiles of $\mathbf{P} \mathbf{1}_{\mathbf{H}}$ recorded upon heating; (b) Temperature dependence of full width at half maximum (FWHM) of the first scattering peak shown in (a); (c) 1D XRD patterns of $\mathbf{P} \mathbf{1}_{\mathbf{H}}$ recorded at different times during isothermal annealing at $135^{\circ} \mathrm{C}$, (d) FWHM of the first scattering peak shown in (c) as a function of annealing time. 

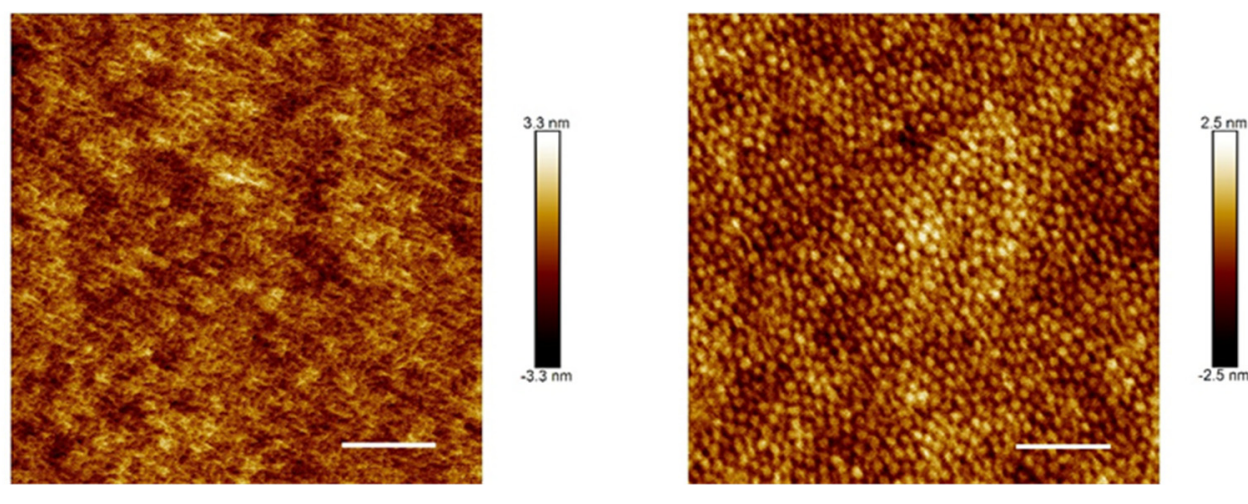

a

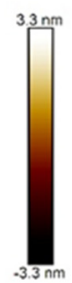

b
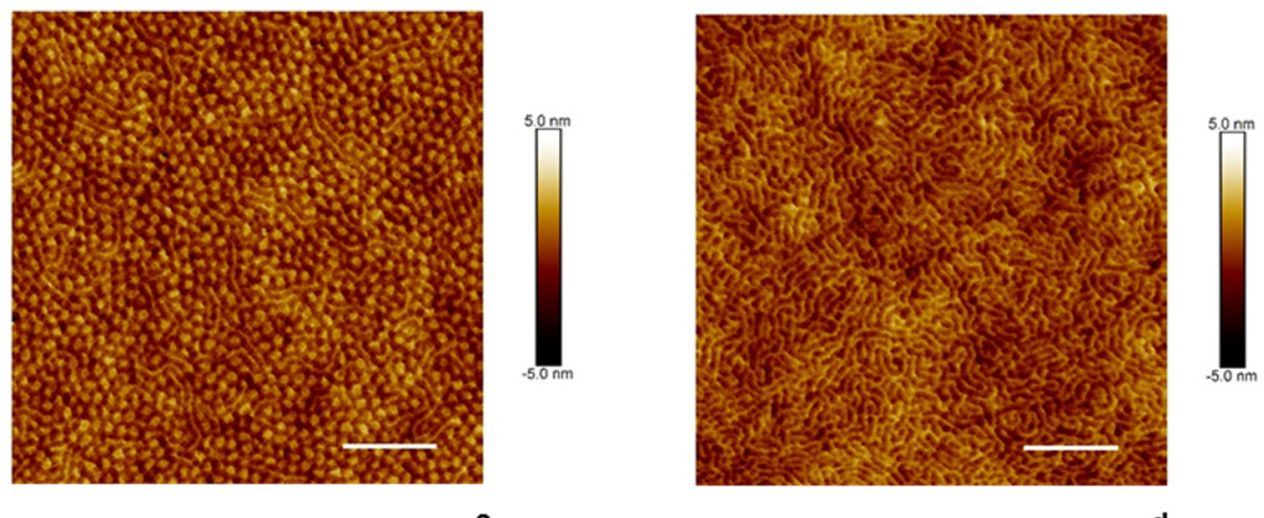

d

Figure S8. AFM results of $\mathbf{P}_{\mathbf{L}}$ after annealing at $110{ }^{\circ} \mathbf{C}$ for different times. (a) before annealing, (b) $1 \mathrm{~h}$, (c) $6 \mathrm{~h}$, (d) $12 \mathrm{~h}$. Scale bar: $100 \mathrm{~nm}$.

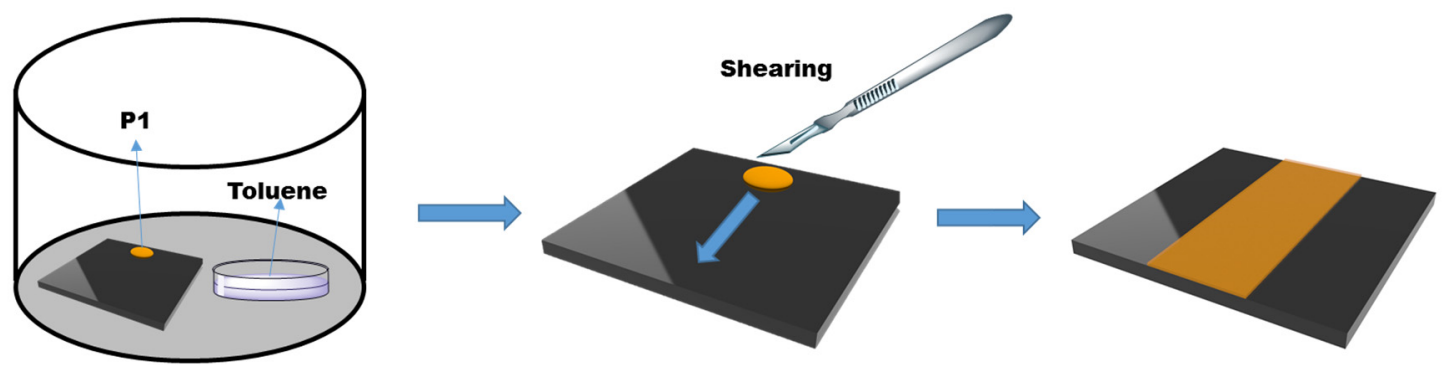

Figure S9. Schematic illustration of the orientation process of P1 on the silicon substrate by mechanical shearing. 
Table S1. Relative integrated intensities, experimental and calculated d-spacings, and phases used in the reconstruction of electron densities for the $\mathrm{Cub} / \mathrm{Im} \overline{\mathbf{3}} \boldsymbol{m}$ phase of $\mathrm{M1}$ at $50^{\circ} \mathrm{C}$. All intensity values are Lorentz corrected and normalized to that of the (400) reflection ${ }^{[6]}$, the "correct" map was selected based on the merit of the maps, helped by the prior physical and chemical knowledge of the system.

\begin{tabular}{|c|c|c|c|c|}
\hline Index & Intensity & $\mathbf{d}_{\text {obs-spacing(nm) }}$ & $\mathbf{d}_{\text {cal-spacing(nm) }}$ & phase \\
\hline 211 & 0.4 & 6.98 & 6.99 & + \\
\hline 310 & 1.3 & 5.42 & 5.42 & + \\
\hline 222 & 7.3 & 4.95 & 4.95 & + \\
\hline 321 & 59.7 & 4.58 & 4.58 & - \\
\hline 400 & 100.0 & 4.28 & 4.29 & + \\
\hline 411 & 2.5 & 4.04 & 4.04 & - \\
\hline 420 & 5.9 & 3.83 & 3.83 & + \\
\hline 422 & 0.5 & 3.50 & 3.50 & - \\
\hline 431 & 3.0 & 3.36 & 3.36 & + \\
\hline
\end{tabular}

\section{References}

[1]. Zhao, R. Y.; Zhao, T. P.; Jiang, X. Q.; Liu, X.; Shi, D.; Liu, C. Y.; Yang, S.; Chen, E. Q. Thermoplastic high strain multishape memory polymer: side-chain polynorbornene with columnar liquid crystalline phase. Adv. Mater. 2017, 29, 1605908.

[2]. Liu, X. Q.; Wang, J.; Yang, S.; Chen, E. Q. Self-organized columnar phase of side-chain liquid crystalline polymers: to precisely control the number of chains bundled in a supramolecular column. ACS. Macro. Lett. 2014, 3, 834-838.

[3]. Zheng, J. F.; Liu, X.; Chen, X. F.; Ren, X. K.; Yang, S.; Chen, E. Q. Hemiphasmidic side-chain liquid crystalline polymer: from smectic $\mathrm{C}$ phase to columnar phase with a bundle of chains as its building block. ACS. Macro. Lett. 2012, 1, 641-645.

[4]. Wen, H.; Zhou, J. H.; Pan, W.; Li, Z. B.; Liang, D. H. Assembly and reassembly of polyelectrolyte complex formed by poly(ethylene glycol)-block-poly(glutamate sodium) and $\mathrm{S}_{5} \mathrm{R}_{4}$ peptide. Macromolecules 2016,49, 4627-4633.

[5]. Teraoka, I. Polymer solutions: an introduction to physical properties. John Wiley \& Sons, Inc., New York, 2002, pp. 43-46.

[6]. Zeng, X. B.; Ungar, G.; Imperor-Clerc, M. A triple-network tricontinuous cubic liquid crystal. Nat. Mater. 2005, 4, 562-567. 